\title{
ÉTICA Y UNIVERSIDAD
}

\section{Carlos de la Isla*}

\section{La situación presente del mundo}

produce asombro y desconcierto. Para el pensamiento crítico y reflexivo es causa de angustia. Es dramático contemplar el cúmulo de problemas en todos los ámbitos y de todas las dimensiones y, al mismo tiempo, descubrir que las soluciones son difíciles, muy difíciles o imposibles.

La ciencia y la técnica han avanzado desmesuradamente, pero no han sabido resolver los más graves problemas humanos. Su avance ha beneficiado a grupos de poder que, para construir y defender su reino del absurdo, han generado armas, guerras, violencia y dominación.

Puede considerarse un fracaso el poder de un saber que beneficia a unos cuantos y que soporta el desprecio, la humillación y explotación de las grandes mayorías. Un saber que no beneficia a toda la humanidad no es un saber humano, sino inhumano.

La ética y la educación están emparentadas por sus fines: el crecimiento y plenificación de las personas. El quehacer esencial de la universidad es proporcionar un ambiente que favorezca el desarrollo y la realización de todos sus integrantes, y, a través de ellos, beneficiar a la sociedad entera. La ética universitaria tiene a su cargo mostrar los medios y elementos más convenientes y debidos para la construcción de ese ambiente y el cumplimiento de sus fines.

La primera prescripción de la ética a la universidad es su compromiso con la verdad por el ejercicio del pensamiento. Ya ésta es una excelente e indispensable tarea. Así como todo sistema filosófico se

\footnotetext{
* Departamento Académico de Estudios Generales, ITAM.
} 
CARLOS DE LA ISLA

inicia con el problema de la verdad, de la legitimación del conocimiento para justificar otras incursiones en la cosmología, en la metafísica, en la estética... así la Universidad debe empezar por abrir la puerta que conduce al mundo de verdades y no de falsedades.

Esto que parece una obviedad tiene una inmensa relevancia, porque vivimos en un mundo de sombras y mentiras. José Saramago en su libro La caverna exclama: "Cavernícolas de todo el mundo salid de la cueva.” No es un tema nuevo ni una nueva realidad, pero el tamaño de las falsedades y de las sombras ha aumentado en forma descomunal. Ya hace veinticuatro siglos Platón usa la metáfora y describe el mito de la caverna. El terrible significado que entraña es que los que están en la cueva sólo perciben sombras y juran que son la única realidad. Desde esa perspectiva no es posible conocer verdad alguna, porque sólo aparecen falsedades que se toman por verdades. Por eso el filósofo griego después afirma: la educación consiste en caminar el camino que conduce de las sombras a la luz, del mundo de las mentiras al mundo de las verdades; consiste en salir de la caverna y avanzar hacia la iluminación del sol.

Éste es verdaderamente el deber ético más importante de la universidad: mostrar, iluminar a los estudiantes la puerta de la caverna para salir de ella y auxiliarlos en la escabrosa y dolorosa demostración y reconocimiento de las sombras como sombras.

Algunas universidades consideran que avanzan en esa dirección cuando enseñan los conocimientos oficiales. Pero éstos pueden ser enseñanzas de sombras o sólo relaciones de sombras con sombras. Y ésta es la manera en que se ha agrandado la cavidad de la caverna.

Los ejemplos son infinitos: ¿cómo llamar democracia a un régimen de unos cuantos (oligarquía) ricos (plutocracia) que imponen sus caprichos a las mayorías (tiranía) en un sistema de abusos y desigualdades (capitalismo)? ¿Alguien podrá negar que ésa es la sombra, la gran mentira de la democracia? y ¿qué decir de la educación pensada como fórmula de éxito económico, para la competencia globalizada, para obtener más y mejores conocimientos vendibles? ¿No es ésta la forma dominante, la gran mentira de la educación? 
ÉTICA Y UNIVERSIDAD

¿Y la globalización como sistema político, social, económico, cultural para beneficio de todos, que convierte al planeta en una aldea próspera y solidaria, no es la globalización de la gran mentira que en los hechos entraña la mundialización de la injusticia, del odio, de la violencia...?

¿Y el Estado de derecho, y el imperio de la ley, y el reparto de la mano invisible, y la producción de la abundancia, y la legitimación del poder, la justificación de la guerra, de las armas, de los 'encargos' de Dios, de la superioridad de los ‘superiores'...? Son éstos sólo breves, brevísimos ejemplos de las sombras, de las infames mentiras que se tienen por verdades en la cueva de este mundo. ¡Qué importante es que "los cavernícolas del mundo salgan de la cueva”!

¡Excelente obligación ética de la universidad: demostrar que las sombras son sombras y que hay que recorrer el camino hacia la luz!

Este deber de la universidad es excelente, pero también difícil y arriesgado, porque los guardianes y constructores de las sombras y los custodios de la caverna son inmensamente poderosos y su poder se sustenta en su reino de mentiras.

Esto no significa que la universidad deba ser la casa donde habite toda la verdad. Pero sí significa que no debe producir ni propagar las sombras, que no debe asociarse con sus productores; que no siembre mentiras con ropajes de verdades, y que transite el camino (método) de la búsqueda que ilumina.

Más que repartir y derramar ‘ciencias’, que fecunde el entendimiento crítico con poder de discernir, de reconocer, de descubrir lo que podemos conocer de la verdad de las personas y de las cosas. Más que esforzarse en engordar los cerebros y en amaestrar con saberes por saberes de la cueva la universidad debe cultivar con pasión el amor y el placer de saber y debe generar verdad que se convierta en vida y libertad. ¡Qué trascendente deber ético de la universidad!

Íntimamente relacionada con el tema de la verdad surge la necesidad ética de la responsabilidad social como expresión de justicia, indispensable también para el cambio social. 


\section{CARLOS DE LA ISLA}

Muy pocas veces los universitarios (estudiantes, profesores, funcionarios) se esfuerzan en inventar el cambio y menos en promoverlo. La inmensa mayoría de ellos pertenecen a la notable y reducida esfera de los beneficiados, y por eso, sensible y apasionadamente procuran la permanencia y fortalecimiento de las teorías, sistemas, políticas y cosmovisiones que han mantenido la fortaleza de los propios privilegios.

Los argumentos de la clase dominante son tan numerosos como vacíos: Siempre han habido ricos y pobres; los que tienen poseen el derecho de hacer lo que quieren con sus propiedades; ya nacemos diferentes; las igualdades son contrarias a la naturaleza; no se trata de repartir pobrezas y lágrimas; es necesario producir abundancia para repartirla..., y no falta el silogismo sobre el destino divino de los ricos y de los miserables.

Es una grave obligación de la universidad formar en los estudiantes un criterio de justicia a partir del sentido común, de las concepciones de los grandes filósofos y, en especial, de las evidentes razonadas virtudes éticas de la justicia social. Esta labor universitaria es muy difícil, porque las ideas de dominación se heredan, se reproducen, se defienden como los propios bienes. Estas ideologías se trasmiten de padres a hijos casi por procesos genéticos, pero, además, los mismos grupos de poder construyen las instituciones sociales, políticas, financieras para custodiar sus inmensos intereses: medios de comunicación, partidos políticos, legislación, consorcios industriales y comerciales en el ámbito nacional e internacional.

Uno de los instrumentos más cuidados y mejor elaborados de este aparato de defensa y conservación de privilegios es el sistema educativo. Se producen escuelas y universidades buenas, malas y pésimas. Las buenas y caras son el recinto donde se enseñan y se aprenden las 'verdades', las ciencias y las técnicas de la prosperidad, del progreso, de la producción de la abundancia para mantener la 'clase'. Las malas deben producir mandos intermedios sumisos, obedientes, hechos para funcionar bien. Las pésimas también son necesarias para generar la otra clase, la de los ignorantes e incondicionales por necesitados, la de 
ÉTICA Y UNIVERSIDAD

la mano de obra barata que pueda competir con la más barata del mundo para atraer las inversiones que buscan las utilidades sin límites.

El sistema educativo construido así y con esos fines es un sistema perverso, porque produce una sociedad de injusticias, de odio y de violencia por medio de la educación, que debiera elevar y hermanar a todos los seres humanos.

Un sistema político que produce, o por lo menos tolera, el menosprecio y hasta el desprecio de una educación igualitaria es intrínsecamente inhumano, porque no sólo destruye el bien común que legitima la política, sino que favorece, privilegia el poder del dinero sobre la dignidad de las personas.

Una universidad puede escapar de estas perversiones y complicidades si, y sólo si, como se ha dicho, forma en sus estudiantes una clara y fuerte conciencia de responsabilidad social y si ella misma se compromete con la justicia.

Hay algunos medios indispensables para la formación de esta conciencia ética en la educación. Por la esencia del quehacer universitario, la evidencia intelectual ha de ser el medio más poderoso. Ningún problema existe para demostrar la dignidad intrínseca de los seres humanos, el derecho que tienen a ser tratados como iguales, el derecho, por el sólo hecho de ser personas, de poder disponer de todos los elementos para formular y realizar su proyecto de vida. Los argumentos en favor del Bien Común, de la justicia conmutativa, distributiva y social son indiscutibles por contundentes con demostraciones del sentido común, de la intuición, de la argumentación inductiva y deductiva, desde los grandes griegos hasta las más recientes teorías éticas de la justicia social.

Es obvio, sin embargo, que una cosa es saber qué es la justicia y otra cosa es ser justo; que una cosa es saber qué debemos hacer y otra cosa más difícil es hacer lo que debemos. Por eso las evidencias racionales de la responsabilidad social deben ser tan fuertes que muevan a la acción de la justicia. Mucho ayuda en este proceso la mostración de las terribles injusticias sociales que sublevan cualquier sensibilidad humana que no ha sido destrozada. 
CARLOS DE LA ISLA

Otro medio indispensable para la formación de la conciencia ética de responsabilidad social (que debería ser un requisito para entregar el título universitario) es la práctica de la justicia institucional. Una universidad forma hábitos, actitudes justas si es una universidad donde gobierna la razón y se vive la justicia: Un lugar en el que los estudiantes puedan encontrar los medios y oportunidades convenientes para su desarrollo personal en los planos intelectual, estético, espiritual y moral. Donde los profesores investigan, generan y comunican conocimientos, muestran caminos deseables con sus propias vidas, comunican a sus alumnos el placer de saber, pero también disponen de posibilidades económicas académicas y culturales para crecer y proyectar su crecimiento. Allí los funcionarios están preparados para organizar, decidir, ordenar, innovar, gobiernan y se encargan de ordenar fines y medios de la universidad en todos sus niveles y las personas de la administración y de servicio hacen muy bien lo que les corresponde pero reciben un salario justo (mínima distancia entre justicia distributiva [lo que necesitan para vivir con dignidad] y justicia conmutativa [de acuerdo a lo que producen] y además cuentan con elementos para cultivarse y poder ascender a desempeños más deseables y de mayor calidad.

Es bueno repetirlo, la universidad buena y justa es la que enseña la justicia, siendo justa. Y es buena y justa cuando cada quien hace muy bien lo que le corresponde.

También es deber formativo de la universidad beneficiar a la comunidad circundante y a toda la sociedad con sus aportaciones académicas e intelectuales sobre los problemas vigentes -ampliando su infuencia social, por ejemplo, a través de Extensión universitaria.

Otro elemento muy importante para la formación de una conciencia éticamente responsable es un verdadero Servicio Social. El estudiante debe tener conocimiento de la realidad nacional: las hirientes diferencias sociales, la angustiosa pobreza de la mayoría junto a la obscena abundancia de unos cuantos, el drama del desempleo, la desesperación de los que carecen de hogar o de un simple refugio, los obligados a un trabajo humillante por la necesidad, los marginados de los servicios de salud, de educación, de posibilidades mínimas de una vida con 
ÉTICA Y UNIVERSIDAD

elemental dignidad... Los estudiantes todos deben conocer esta realidad y, mejor todavía, deben experimentarla y procurar solucionarla según sus posibilidades. Esto sería un formativo Servicio Social.

La inversión en la educación superior es enorme. ¡Sería bueno que fuera mayor! La gran injuria es que gran parte de ella se substrae del gasto social. Es decir, se sacrifica más a los más necesitados para favorecer a los educados.

Aquí radica el fundamento del Servicio Social como acto de justicia conmutativa. Los universitarios deben retribuir a la sociedad, por lo menos, en la medida de lo que han recibido. La teoría ética de la justicia social en expresión de Rawls tiene una evidente fórmula: “A todos por igual y las diferencias sólo se justifican cuando favorecen a los más necesitados.” En la realidad que vivimos no se procuran ciertamente las igualdades básicas, y las diferencias favorecen a los ya favorecidos. La realidad que vivimos es un ejemplo perfecto de la más flagrante injusticia social. Las cifras de la patología de la más obesa abundancia junto a la más agónica miseria causada por el sádico poder de explotación, de dominación y de muerte son cifras absolutamente criminales que incitan a la violencia. Y esto, por escandaloso que parezca, es también el escenario en los ‘países democráticos’ por excelencia. ¿Qué especializado cinismo será capaz de llamar democracia a este sistema de desigualdades mortales?

Aquí es donde se agiganta la disyuntiva ética de la universidad: o se entrega incondicionalmente a los brazos del mercado, a las leyes, fines e imperio del mercado o lucha con valentía por la educación, por la dignidad de las personas.

En el primer caso la universidad se convierte en industria productora de mercancía humana devaluada; en el segundo caso la universidad es el recinto de humanidad donde crecen personalidades con potencialidades infinitas; en el primer caso los estudiantes se degradan al ser transformados con cualidades que les dan valor de uso como fundamento de su valor de cambio. En la rebelión estudiantil del 68 los estudiantes protestaron en contra de ser tratados como cosas. Defendían, hasta con las armas, su derecho a ser tratados como personas. 


\section{CARLOS DE LA ISLA}

Parece que el sistema de mercado triunfó y que la mayoría de las universidades fortalecieron su proceso productivo.

Estamos tal vez ante el dilema más crucial de la historia de las universidades: degradación mercantil o humanización y dignidad. La degradación mercantil y la asociación con el sistema de injusticias ya ha avanzado vertiginosamente. Según datos de la ANUIES, de las más de dos mil universidades privadas en México, "más del 93\% dan servicios deficientes y se dedican al fraude” (Milenio, noviembre 2002). Miles de universidades en el mundo son sumisas y favorecen las políticas oficiales para recibir más subsidios; los programas académicos se rigen por la demanda; los contenidos, hasta en materias optativas, están minuciosamente diseñados de acuerdo a las necesidades y preferencias del mercado de las profesiones; el perfil de ese singular "producto universitario”, que ha de ofrecerse y regatearse entre las empresas nacionales, trasnacionales, globalizadas lo trazan y matizan los consorcios gerenciales como se proyecta, se ajusta y se afina una pieza para la maquinaria. Y todavía mayor degradación se produce cuando las universidades sustentan contratos para investigaciones requeridas por organismos involucrados en estrategias políticas beligerantes y hasta en producción de armas.

La otra opción, la de la ética universitaria, la de la universidad como inteligencia crítica de la sociedad, como recinto de humanidad y de dignidad, la de la universidad que sirve inmensamente a la sociedad con la generación del saber, con la trasmisión y proyección de la verdad, la universidad que sirve a la sociedad como el intelecto sirve al hombre, pero que no es servil a los grupos de poderes políticos o económicos, la universidad que mantiene su libertad y autonomía y desde sí misma conoce, juzga y aporta soluciones a los problemas sociales está amenazada y acosada por las imposiciones reinantes.

La actitud defensora de la dignidad universitaria es difícil, y para muchos utópica e irrealizable, sin embargo es la única postura ética defendible, si la universidad no quiere ser cómplice o actor importante de la infamias de este mundo. 
ÉTICA Y UNIVERSIDAD

Uno de los pronósticos más certeros sobre la sociedad contemporánea, en el que coinciden expertos de muy diversos campos, es la patología de la incertidumbre y su engendro de inseguridad. El equilibrio, la homeostasis del mundo ha sido destrozada por los caprichos de los poderosos que se expresan en impulsos temperamentales emanados de la pasión por el poder egocéntrico y por el placer de la dominación.

Esta neurosis es de altísimo riesgo para la humanidad. Es el totalitarismo de la pasión sin freno, es la demencia del poder que se caracteriza por la arbitrariedad y que hace imposible cualquier asiento de certidumbre.

En la reciente reunión de Davos se enfatizó la globalización de lo imprevisible, del galope sin rumbo, de la imposición de la irracionalidad. En un análisis semejante se usaba la metáfora del caballo desbocado que, al cruzar un poblado le gritaron al jinete: ¿a dónde vas? Él contestó: yo no sé, pregúntale al caballo. Es generalizada la idea de un mundo sin rumbo.

En esta situación de tanta obscuridad, confusión e incertidumbre creo que la única institución que puede proyectar luz e iluminar caminos con dirección bien clara es la universidad. Por supuesto, no la universidad mediocre, mercantil o apéndice del sistema, sino la universidad que toma en serio su misión de pensar. Nadie (y la afirmación es categórica) nadie mejor que una buena universidad puede investigar, discutir, discurrir sobre los problemas políticos, económicos y sociales, siempre que mantenga su libertad e independencia para pensar. El fundamento de esta afirmación se sitúa en el supuesto de que en las buenas universidades están las mentes más lúcidas y fecundas que, libres de compromisos políticos o de intereses económicos pueden percibir y expresar las mejores opciones para la salud de la polis.

Las principales razones por las que no han tenido presencia e influencia políticas (en el auténtico sentido del término) es porque las universidades, casi en su totalidad, han estado muy ocupadas en sus ganancias económicas y en sus complacencias mercantiles, y también, porque se han mantenido separadas del cuerpo social. Aun las universidades de buena academia se dedican a enseñar, a titular, a investigar y a cons- 


\section{CARLOS DE LA ISLA}

truir teorías, pero en abstracto, y abstracción es separación; se han interesado de la sociedad para usarla no para beneficiarla.

Esto no sugiere la politización de la universidad que sacrificaría su independencia. Una cosa es hacer política ordinaria (juego de poderes) y otra cosa es aportar opciones y teorías de comportamiento y práctica política. Y esto sí es obligación ética de la universidad.

Tal vez el problema más grave que la universidad debe pensar profundamente para aportar soluciones es la quiebra global del sistema. Lo único que legitima un sistema político es el logro del bien común (conjunto de elementos sociales que propician el desarrollo de todos los ciudadanos). En este mundo del siglo XXI, de cada seis personas, cinco son pobres, muchísimos millones son extremadamente pobres (sin posibilidad alguna de vivir dignamente) y muchísimos millones mueren de hambre, de enfermedades curables y de ignorancia. Este drama no es por destino del planeta. Si se empleara menos del cinco por ciento del gasto en la imbecilidad de la guerra y de las armas en alimentos, medicinas y educación nuestro mundo sería radicalmente más humano. Sólo este dato es suficiente para proclamar, no sólo que este sistema está en quiebra, sino que es intrínsecamente perverso. Hay quienes lo califican de bestial; el adjetivo es injusto, porque entre las bestias no hay rastros de tan vil comportamiento.

La quiebra no sólo es evidente en el plano político. Una economía que se aferra a un libre mercado, supuestamente productor de abundancia y mejor instrumento de distribución y que da como resultado la obscena riqueza de pocos y el desempleo, el hambre y la angustia de las mayorías es también una teoría fracasada.

La quiebra del sistema político y económico ha producido un efecto catastrófico e irreparable: La obsesión consumista, la patología de las compras como disfrute de placer y felicidad, la vaciedad insondable que los ricos quieren llenar con cosas, la eterna insatisfacción que inútilmente procura mitigarse en el mercado, el insaciable placer de tener son algunas causas de la destrucción de la casa del hombre: contaminación despiadada de ríos, de lagos y mares, deforestación agresiva de las zonas más abundantes de especies, erosión calcinada, daño a 
ÉTICA Y UNIVERSIDAD

las capas protectoras de la atmósfera, rompimiento del finísimo equilibrio biológico, calentamiento creciente del ambiente y sus múltiples efectos...

Esta agresión destructora de la naturaleza, de la ecología es sin duda la consecuencia más grave de las actuales cosmovisiones y modos de vida, porque los daños pueden ser mortales y ciertamente irreversibles.

Ante este peligroso y evidente fracaso de las estructuras y sistemas existentes, la universidad es la única verdadera opción y esperanza. Los políticos seguirán defendiendo sus beneficios, los hombres de negocios seguirán promoviendo sus ganancias, los economistas seguirán exaltando el mercado y sus encantos, las empresas trasnacionales seguirán agrandando sus arcas insondables y explotando miserablemente a los miserables, los ‘media’ seguirán usando todos los medios para mediatizar y manejar el mundo como a los títeres los titiriteros.

Un cambio de este mundo de crueldades, injusticias, mentiras y arbitrariedades no podrá venir de los poderosos autores ni de sus obras que ellos han construido. La opción de las armas se ha manifestado muy explicable, pero contraproducente y sanguinaria. Así, queda como única opción y esperanza la acción y pasión en la revolución del pensamiento.

\section{Reiteración en síntesis final}

Es un vehemente clamor de la ética a la universidad: ¡Que realice el supremo deber de pensar y que se comprometa con una sociedad mucho más justa, libre y humana! Pero que no se limite a pensar lo pensado, que no se someta el entendimiento a su encierro en el archivo de la memoria. ¡Ya basta de que el estudiante más premiado y elogiado sea el más fiel repetidor, el más sumiso al pensamiento programado, el más vasto recipiente!

Éste es el sistema de la perpetuación de las ideas y modos de vida que han procreado los privilegios ofensivos y las explosiones de violencia y desesperación. ¡Ya es hora de que estudiantes y profesores sean 


\section{CARLOS DE LA ISLA}

más apreciados por sus creaciones, por sus invenciones, por su amor a la verdad, a la justicia, a la dignidad de las personas!

Es necesario, es indispensable que la universidad se concentre en la educación total, porque la única verdadera esperanza de un mundo mejor es la generación del hombre humano. Y sólo las buenas universidades pueden ser campos de siembra y desarrollo de humanidad.

¡Hay que decirlo muchas veces: La universidad sí puede, sí debe transformar el mundo por la gran calidad de sus profesores, de sus investigadores, de sus estudiantes y de sus egresados! Debe realizar su misión, instalada como conciencia crítica de la sociedad, con su labor ética, con su voz fuerte y autorizada por su libertad, independencia y autonomía, por su honestidad y por la defensa de los grandes bienes de todos los hombres. Ésta es la única esperanza, la única verdadera esperanza. ¡Inmensa responsabilidad de la Universidad!

Platón, el gran filósofo griego, era aristócrata y pertenecía a la porción más privilegiada de Atenas; sin embargo, movido por sus convicciones sobre la justicia se lanzó a procurar las extremas igualdades que había imaginado en su República. Se dice que pretendió convencer al tirano Dionisio de su sistema de sabiduría y equidad. El resultado era previsible: los poderosos sintieron amenazados sus privilegios; lo persiguieron, lo encarcelaron y finalmente lo vendieron como esclavo. Ya se sabe la otra parte de este relato: con el dinero que se pagó por el esclavo Platón se fundó la Academia, la primera universidad de Occidente.

Si se trata de un hecho real parece legítimo pensar que cuando Platón no pudo cambiar el sistema injusto y tiránico acudió a fundar aquel recinto del pensamiento, comunidad dedicada a pensar, la universidad como el mejor medio para transformar el mundo. "Lo que yo no pude hacer lo podrá hacer la Academia.” Seguramente así pensó el gran filósofo griego. 